\title{
Developmental Remodeling of Thalamic Interneurons Requires Retinal Signaling
}

\author{
Naomi E. Charalambakis, Gubbi Govindaiah, Peter W. Campbell, and William Guido \\ Department of Anatomical Sciences and Neurobiology, University of Louisville School of Medicine, Louisville, Kentucky 40292
}

The dorsal lateral geniculate nucleus (dLGN) of the mouse is a model system to study the development of thalamic circuitry. Most studies focus on relay neurons of dLGN, yet little is known about the development of the other principal cell type, intrinsic interneurons. Here we examined whether the structure and function of interneurons relies on retinal signaling. We took a loss-of-function approach and crossed GAD67-GFP mice, which express GFP in dLGN interneurons, with math5 nulls (math $5^{-1-}$ ), mutants that lack retinal ganglion cells and retinofugal projections. In vitro recordings and 3-D reconstructions of biocytin-filled interneurons at different postnatal ages showed their development is a multistaged process involving migration, arbor remodeling, and synapse formation. Arbor remodeling begins during the second postnatal week, after migration to and dispersion within dLGN is complete. This phase includes a period of exuberant branching where arbors grow in number, complexity, and field size. Such growth is followed by branch pruning and stabilization, as interneurons adopt a bipolar architecture. The absence of retinal signaling disrupts this process. The math $5^{-I-}$ interneurons fail to branch and prune, and instead maintain a simple, sparse architecture. To test how such defects influence connectivity with dLGN relay neurons, we used DHPG [(RS)-3,5-dihydroxyphenylglycine], the GGluR $_{1,5}$ agonist that targets $\mathrm{F} 2$ terminals. This led to substantial increases in IPSC activity among WT relay neurons but had little impact in math $5^{-1-}$ mice. Together, these data suggest that retinal signaling is needed to support the arbor elaboration and synaptic connectivity of dLGN interneurons.

Key words: dorsal lateral geniculate nucleus; intrinsic interneurons; mouse; retinogeniculate; thalamus

\section{Significance Statement}

Presently, our understanding about the development of the dorsal lateral geniculate nucleus is limited to circuits involving excitatory thalamocortical relay neurons. Here we show that the other principal cell type, intrinsic interneurons, has a multistaged developmental plan that relies on retinal innervation. These findings indicate that signaling from the periphery guides the maturation of interneurons and the establishment of inhibitory thalamic circuits.

\section{Introduction}

The dorsal lateral geniculate nucleus (dLGN) of the mouse has become a preeminent model system to understand many aspects of thalamic circuit development (Huberman et al., 2008; Hong and Chen, 2011; Seabrook et al., 2017; Guido, 2018). The advance of sophisticated genetic tools and widespread use of genetically modified mouse strains permit remarkable experimental access to study how specific cell types and circuits are established during early postnatal life. However, our understanding of thalamic circuit development has been largely limited to thalamocortical

Received Aug. 21, 2018; revised Feb. 4, 2019; accepted Feb. 26, 2019.

Author contributions: N.E.C., G.G., and W.G. designed research; N.E.C., G.G., P.W.C., and W.G. performed research; N.E.C., G.G., and W.G. analyzed data; N.E.C. and W.G. wrote the paper.

This work was supported by National Institutes of Health Grant EY-12716. We thank Barbara 0'Steen for expert technical support.

The authors declare no competing financial interests.

Correspondence should be addressed to William Guido at william.guido@louisville.edu.

https://doi.org/10.1523/JNEUROSCI.2224-18.2019

Copyright $@ 2019$ the authors neurons, which serve as the exclusive relay of retinal information to the visual cortex. These neurons undergo substantial remodeling during the first few postnatal weeks, developing a complex and stereotypic dendritic architecture that defines their cell class specificity (Krahe et al., 2011; El-Danaf et al., 2015). Such growth is accompanied by the synaptic pruning of retinal connections, whereby the number of functional inputs onto dLGN relay neurons are greatly reduced (Chen and Regehr, 2000; Jaubert-Miazza et al., 2005; Cheadle et al., 2018; Tschetter et al., 2018). Many of these changes rely on retinal signaling. For example, the elimination of retinal input to dLGN leads to dystrophic dendritic growth (El-Danaf et al., 2015), and the blockade of early retinal activity results in synaptic weakening and a failure to prune excess retinal inputs onto developing dLGN relay neurons (Hooks and Chen, 2006).

By comparison, our knowledge about the development of the other dLGN cell type, intrinsic interneurons, remains rudimentary. These local circuit neurons, which receive retinal input, comprise $<10 \%$ of total dLGN cell population (Evangelio et al., 
2018). Despite their small numbers, they play a key role in retinogeniculate signal transmission by sharpening the spatiotemporal receptive field structure of dLGN relay neurons through a feedforward inhibitory circuit (Cox and Sherman, 2000; Bickford et al., 2010; Hirsch et al., 2015).

The recent use of the GAD67-GFP (green fluorescent protein) transgenic strain, which expresses GFP in dLGN interneurons, has led to a number of important discoveries about their genesis, migration, and assembly of inhibitory synaptic connections (Seabrook et al., 2013b; Golding et al., 2014; Jager et al., 2016). Thalamic interneurons migrate to dLGN at perinatal ages, distributing themselves evenly throughout the nucleus by the end of the first postnatal week (Golding et al., 2014; Jager et al., 2016). While interneurons receive retinal input at early postnatal ages, the formation of inhibitory connections occurs much later, well after the maturation of dLGN relay neurons and the initial phase of retinogeniculate synapse remodeling (Bickford et al., 2010; Seabrook et al., 2013b). What is lacking is an understanding about how these milestones relate to the morphological and functional development of interneurons, and whether retinal signaling is needed.

To examine these issues, we used the GAD67-GFP mouse to target developing dLGN interneurons during in vitro intracellular recordings. To assess whether retinal signaling plays a role in the development of their morphological and functional properties, we used a genetic form of retinal deafferentation by using the math5-null (math5 ${ }^{-/-}$) mouse and crossing it onto the GAD67GFP strain. These mutants lack the math5 gene that is required for retinal progenitors to differentiate into retinal ganglion cells (RGCs; Brown et al., 1998; Wang et al., 2001). As a result, math $5^{-1-}$ mice display a $>95 \%$ loss of RGCs, a failure of the surviving RGCs to form an optic nerve, and central visual structures that are devoid of retinal input (Brown et al., 2001; Wang et al., 2001; Wee et al., 2002; Brzezinski et al., 2005; Hammer et al., 2014; El-Danaf et al., 2015). While math5 is transiently expressed in developing retina (Brown et al., 1998, 2001; Wang et al., 2001), and in some hindbrain regions (Saul et al., 2008) it is absent from retinorecipient structures such as suprachiasmatic nucleus and dLGN (Wee et al., 2002; Brzezinski et al., 2005; El-Danaf et al., 2015). In dLGN, there is no sign of retinal terminals or roundshaped vesicles, large size, and pale mitochondria (RLP) synaptic profiles in math $5^{-1-}$ mice (Hammer et al., 2014; El-Danaf et al., 2015). These mutants also show a loss of circadian photoentrainment (Wee et al., 2002; Brzezinski et al., 2005), and they are unable to perform above chance levels on a simple visual discrimination task (Monavarfeshani et al., 2018). This loss-of-function approach is advantageous to postnatal manipulations such as enucleation or optic nerve section. While "eyeless" phenotypes exist in the mouse, they are problematic because they involve a polygenic form of inheritance and additional mutations that likely have a deleterious impact on neuronal development (Cullen and KaisermanAbramof, 1976; Tucker et al., 2001; Verma and Fitzpatrick, 2007). Thus, we used math $5^{-1-}$ mice along with age-matched wild-type (WT) GAD67-GFP mice to understand whether retinal signaling influences interneuron structure, function, and establishment of synaptic connectivity with dLGN relay neurons.

\section{Materials and Methods}

Animals. Experiments were conducted in mice of either sex ranging in age between P0-P45. Two strains were used: GAD67-GFP (line G42; stock \#007677, The Jackson Laboratory) established on a pigmented background $(\mathrm{C} 57 / \mathrm{B} 6 \times \mathrm{CB} 6 \mathrm{~F} 1 / \mathrm{J})$, and math $5^{-1-}$ crossed onto GAD67. The math $5^{-1-}$ strain was on a mixed C57/B6 and 129/SvEv background

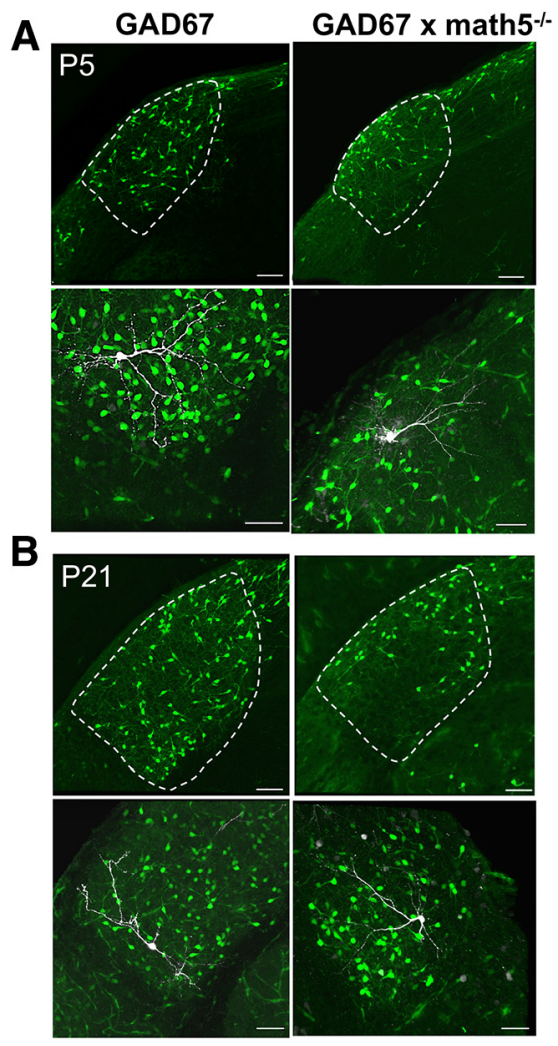

Figure 1. GFP-expressing interneurons in $\mathrm{dLGN}$ of WT and math $5^{-1-}$ mice. $A$, Coronal sections of dLGN from a P5 GAD67 WT mouse (left) and math $5^{-1-}$ mouse (right) crossed onto the GAD67 strain. Top, In WT, interneurons are evenly distributed throughout dLGN; however, in math $5^{-1-}$ mice, migration is disrupted, and they cluster in the dorsolateral region (Golding et al., 2014). Scale bar, $70 \mu \mathrm{m}$. Bottom, Examples of GFP-expressing interneurons that were filled with biocytin during in vitro intracellular recordings and used for 3-D reconstructions. Scale bar, $40 \mu \mathrm{m}$. B, Coronal sections of dLGN from P21 WT and math $5^{-1-}$ mice. Top, Distribution of GFP-expressing interneurons in dLGN. Bottom, Examples of biocytin-filled interneurons.

(Wang et al., 2001; El-Danaf et al., 2015). All procedures approved by the University of Louisville Institutional Animal Care and Use Committee.

Acute in vitro thalamic slice preparation and whole-cell recording procedures. We used an acute thalamic slice preparation and conducted wholecell recordings on dLGN neurons using methods described in detail previously (Govindaiah and Cox, 2006; Seabrook et al., 2013b; El-Danaf et al., 2015). Briefly, mice were anesthetized with isoflurane and decapitated, and excised brains were placed in the following $4^{\circ} \mathrm{C}$ oxygenated (95\% $\mathrm{O}_{2} / 5 \% \mathrm{CO}_{2}$ ) slicing solution (in mM[sCAP]): $26 \mathrm{NaHCO}_{3}, 234$ sucrose, $10 \mathrm{MgSO}_{4}, 11.0$ glucose, $2.5 \mathrm{KCl}, 1.25 \mathrm{NaH}_{2} \mathrm{PO}_{4}$, and $0.5 \mathrm{CaCl}_{2}$. A vibratome (model VT1200S, Leica) was used to make 270 - $\mu \mathrm{m}$-thick coronal sections containing dLGN. Slices were placed for at least $30 \mathrm{~min}$ in a $32^{\circ} \mathrm{C}$ oxygenated artificial CSF (ACSF; in mM: $126 \mathrm{NaCl}, 26 \mathrm{NaHCO}_{3}, 2.5$ $\mathrm{KCl}, 1.25 \mathrm{NaH}_{2} \mathrm{PO}_{4}, 2 \mathrm{MgCl}_{2}, 2 \mathrm{CaCl}_{2}$, and 10 glucose), and then maintained at room temperature. Throughout the recording, slices were continuously perfused in an oxygenated solution of ACSF $(2.5 \mathrm{ml} / \mathrm{min} ; 95 \%$ $\mathrm{O}_{2} / 5 \% \mathrm{CO}_{2}$ ) and maintained at $32^{\circ} \mathrm{C}$.

Whole-cell recordings were obtained in both current-clamp and voltage-clamp mode using a chamber that was mounted on an upright microscope (model BX51WI, Olympus) equipped with differential interference contrast and florescence optics to visualize GFP-expressing interneurons. Recordings were made using a Multiclamp 700B Amplifier (Molecular Devices), filtered at $310 \mathrm{kHz}$ and digitized (1440A Digitizer, Digidata) at $10 \mathrm{kHz}$. Patch electrodes made of borosilicate glass were pulled using a vertical puller (model PC-10, Narishige) with a final tip resistance between 4 and $7 \mathrm{M} \Omega$.

For current-clamp recordings, electrodes were filled with an internal solution containing the following (in $\mathrm{mM}$ ): $117 \mathrm{~K}$-gluconate, $13.0 \mathrm{KCl}, 1$ $\mathrm{MgCl}_{2}, 0.007 \mathrm{CaCl}_{2}, 0.1$ EGTA, 10 HEPES, $2 \mathrm{Na}$-ATP, and 0.4 Na-GTP. 
To examine the passive and active membrane properties of interneurons, we recorded the voltage responses evoked by square wave current pulses $(-120$ to $+150 \mathrm{pA})$ of varying duration and intensity $(600-1000 \mathrm{~ms}, 15 \mathrm{pA}$ increments). Input resistance was calculated by measuring the amplitude at rest to a small hyperpolarizing current pulse $(-15 \mathrm{pA})$. Spike firing frequency (in $\mathrm{Hz}$ ) was based on the maximal firing rate evoked by a large depolarizing current step $(+15$ to $+150 \mathrm{pA}$; step size, $15 \mathrm{pA}$ ) and calculated by counting the number of spikes divided by the first $600 \mathrm{~ms}$ of the current pulse. To estimate the strength of the mixed cation conductance $\left(\mathrm{I}_{\mathrm{H}}\right)$, we used a series of hyperpolarizing pulses $(-120$ to $-15 \mathrm{pA}$; step size, $15 \mathrm{pA}$ ) and calculated the amplitude of the largest inward rectifying response. The degree of inward rectification $\left(V_{\mathrm{sag}}\right)$ was determined by measuring the relative change between the maximal voltage response $\left(V_{\max }\right)$ and steadystate voltage response $\left(V_{\mathrm{ss}}\right)$, as follows: $\left(V_{\max }-\right.$ $\left.V_{\text {ss }} / V_{\max }\right) \times 100$ (Leist et al., 2016). All measurements were performed at the resting membrane potential (RMP; -55 to $-48 \mathrm{mV}$ ).

To record IPSCs, we conducted voltageclamp recordings from dLGN relay neurons at $0 \mathrm{mV}$ using a cesium-based internal solution containing the following (in $\mathrm{mm}$ ): 117 Csgluconate, $11 \mathrm{CsCl}, 1 \mathrm{MgCl}_{2}, 1 \mathrm{CaCl}_{2}, 0.1$ EGTA, 10 HEPES, $2 \mathrm{Na}_{2}$-ATP, and $0.4 \mathrm{Na}_{2}-$ GTP. Concentrated stock solution of (RS)3,5-dihydroxyphenylglycine (DHPG; catalog $\# 0342$, Tocris Bioscience) was prepared and stored as recommended. The agonist was diluted in ACSF to its final concentration (50 $\mu \mathrm{M})$ before use and applied via a short bolus into the input line of the recording chamber using a syringe pump (Govindaiah and Cox, 2006).

IPSCs were detected and analyzed with Mini Analysis software (Synaptosoft) using threshold (10 pA) and waveform detection protocols established by (Govindaiah and Cox, 2006). To quantify spontaneous IPSCs (sIPSCs), the average frequency and amplitude were averaged from $120 \mathrm{~s}$ windows before metabotropic glutamate receptor $1,5\left(\mathrm{mGluR}_{1,5}\right)$ agonist administration (Pre) and after agonist administration (Post).

For all recordings, biocytin $(0.5 \%)$ was included in the internal solution to allow for intracellular filling and subsequent 3-D reconstruction using confocal microscopy. Following the completion of the recording session, slices were fixed overnight with $4 \%$ paraformaldehyde in 0.1 M PBS (pH 7.2). To visualize biocytin-filled interneurons, slices were washed with PBS $(3 \times, 10 \mathrm{~min}$ each) and incubated overnight in a PBS solution containing $0.1 \%$ Triton X-100 and $0.1 \%$ Alexa Fluor 647-conjugated streptavidin (catalog \#S21374, Invitrogen). The following day, slices were washed in PBS ( $3 \times, 10 \mathrm{~min}$ each), mounted with ProLong Gold with DAPI (catalog \# P36931, Invitrogen), and coverslipped for confocal imaging.

3-D reconstructions of biocytin-filled interneurons. Biocytin-filled interneurons were imaged using a multiphoton laser-scanning confocal microscope (model \#FV1200BX61, Olympus). An HeNe laser (635 nm) was used to excite far-red, biocytin fluorescence. Neurons were imaged using a $10 \times[0.3$ numerical aperture $(\mathrm{NA})]$ or $20 \times(0.75 \mathrm{NA})$ objective lens at a scanning resolution of $1600 \times 1600$ pixels. A sequential series of optical slices with an optimal step size through the $z$-axis of $1.26 \mu \mathrm{m}$ $(20 \times / 0.75$ NA lens $)$ created a $3-D, Z$-stack dataset. Three-dimensional reconstructions and analyses were performed using Imaris software (version 8.4.1, Bitplane). Soma area was measured by using the "Surface" function tool, and highlighting the soma in the $x, y$, and $z$ planes. Branch reconstruction was generated in the $z$-plane by using the "Filament tracer" function and verified by visual inspection. The total number of branches was determined by using the "Total Number of Terminal Points" tab in the Filament function. To evaluate the degree of arbor complexity, we labeled the filament-generated arbor tree using the "Statistics Coded Color" tab. This automated tool uses the soma as the starting point, and traces the arbor tree according to the $n$th order branch. The "Statistics" tab was used to calculate the average and maximal branch order for each interneuron. To measure the volume of the arbor field, we started with the filament reconstruction, and used the "Convex Hull XTension" function in the Tools tab. This feature creates a new surface object superimposed on the filament. The convex polyhedron envelops all distal points (i.e., distal processes) of the selected filament and is used to calculate volume.

Enucleation. Binocular enucleation (BE) was performed on WT GAD67-GFP mice (two male and two female mice) $36 \mathrm{~h}$ after birth 
[postnatal day 1.5 (P1.5)]. Under deep anesthesia, the palpebral fissure was opened, and the eyeball was isolated using a pair of curved forceps. The optic nerve and the ophthalmic artery were then cut, and the eye was carefully removed. The orbit was filled with Gelfoam to avoid hemorrhaging. Animals were allowed to recover on a heating pad and were then returned to their home cages.

Experimental design and statistical analysis. All statistical tests were performed using either SigmaPlot 11.0 (Systat Software) or Prism 7.0 (GraphPad Software). To test for normality, we used the Shapiro-Wilk Normality and Equal Variance Test. A two-way ANOVA was used to examine age-related differences within a group (WT or math $5^{-1-}$ ) and between groups across the various morphological features (e.g., soma area, arbor complexity, arbor field volume) and membrane properties ( $V_{\text {sag, }}$, firing frequency). The post hoc Holm-Sidak method allowed for pairwise multiple comparisons both within group and across postnatal weeks. For pharmacology experiments, we conducted a two-way repeated-measures ANOVA to assess predrug versus postdrug differences in IPSC frequency and amplitude. The post hoc Holm-Sidak method was applied to make multiple comparisons between groups. To compare percentage changes in $\mathrm{mGluR}_{5}$ agonist-mediated responses $[($ Post - Pre/Pre $) \times 100]$, we used the nonparametric Mann-Whitney rank sum test and one-way ANOVA to determine whether median values of frequency and amplitude were different between WT and math $5^{-1-}$, and among WT, math $5^{-1-}$, and BE, respectively. For all statistical tests, $p$ values $<0.05$ were considered significant.

\section{Results}

\section{Morphology of developing interneurons in WT and} math $5^{-/-}$mice

Figure 1 shows examples of coronal sections through the dLGN of P5 (Fig. 1A) and P21 (Fig. 1B) GAD67-GFP (WT) and GAD67 $\times$ math $5^{-1-}$ (math5 ${ }^{-1-}$ ) mice. In both strains, we observed GFP labeling in dLGN interneurons even at early postnatal ages. In WT mice, interneurons are evenly distributed throughout the nucleus (Seabrook et al., 2013b; Golding et al., 2014). However, in math $5^{-1-}$ mice, interneurons failed to migrate properly and clustered in the upper sector of the dLGN. This observation is consistent with previous reports showing that early postnatal elimination of retinal signaling disrupts the migratory path and spacing of dLGN interneurons (Golding et al., 2014). Nonetheless, in both strains we were able to readily identify and target interneurons for recording and biocytin filling.

We generated 3-D reconstructions for a total of 130 biocytinfilled interneurons (WT, $n=64$; math $5^{-1-}, n=66$ ) across the first 4 weeks of postnatal life. Figure 2 provides representative examples of interneuron reconstructions from WT and agematched math $5^{-1-}$ mice arranged by postnatal week. At early ages and in both groups, interneurons had class 3 morphology, displaying expansive and complex arbors that arise from opposite poles of fusiform-shaped soma (Guillery, 1966). Arbors are composed of both dendrites and axons. Not all interneurons have conventional axons, and there is no clear way to distinguish them from dendrites (Lieberman, 1973; Wilson, 1986; Sherman, 2004). Additionally, bead-like protrusions on distal processes (Fig. 2, inset) were especially apparent in WT interneurons after the second postnatal week. It is presumed that these grape-like appendages represent presynaptic dendritic terminal sites (F2 profiles) that form part of a triadic arrangement with a retinal terminal and relay cell dendrite (Szentagothai, 1963; Guillery, 1966; Hamos et al., 1985; Sherman, 2004). Despite the similarities in overall morphology between WT and math $5^{-1-}$ interneurons, the absence of retinal signaling had a dystrophic effect on their growth, and these defects are summarized in Figure 3.

WT interneurons experienced significant growth in soma size between weeks 1 and 2 (Fig. $3 A$, black; $F_{(3,120)}=3.722 ; p=$
A

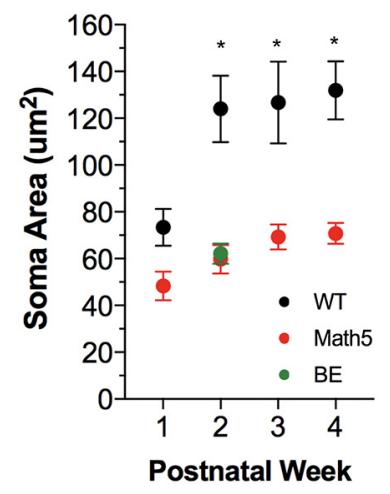

B

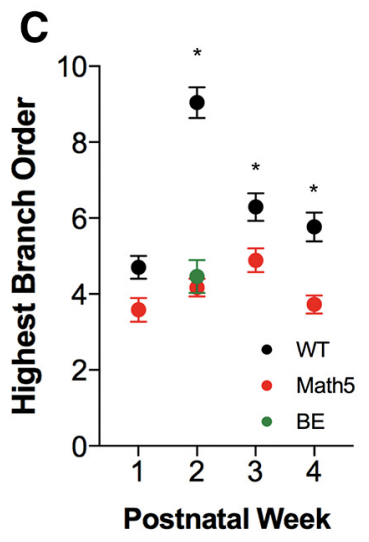

D

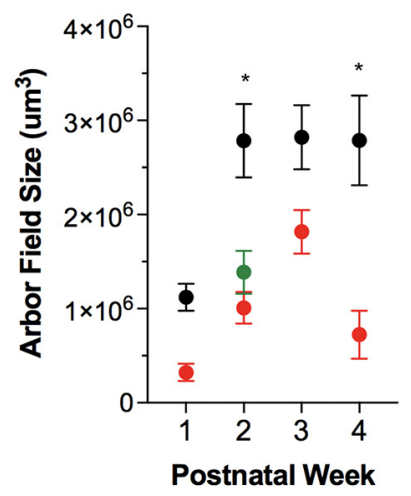

Figure 3. Morphological development of dLGN interneurons in WT, math $5^{-1-}$, and BE mice. $\boldsymbol{A}-\boldsymbol{D}$, Summary plots depicting age-related changes in soma area $(\boldsymbol{A})$, number of processes $(\boldsymbol{B})$, branch complexity $(\boldsymbol{C})$, and arbor field size $(\boldsymbol{D})$ of interneurons in WT (black) and math5 ${ }^{-1-}$ (red) mice. Also shown at postnatal week 2 are mice that underwent BE at P1.5 (green). Each point represents mean values \pm SEM plotted by postnatal week. $\boldsymbol{A}$, Between weeks 1 and 2, WT soma area increased approximately twofold $\left({ }^{*} p=0.026\right.$ ). The math $5^{-1-}$ and BE soma areas are reduced compared with WT soma areas ( ${ }^{*}$ math $5^{-1-}$; week $2, p<$ 0.001; week $3, p=0.0015$; week 4, $p=0.0066$; BE week $2, p=0.0014$ ). $\boldsymbol{B}$, WT interneurons show an increased number of arbor processes between weeks 1 and $2\left({ }^{*} p<0.0001\right)$, followed by a reduction in weeks $3-4$. The math $5^{-1-}$ interneurons show no age-related changes and are reduced compared with WT interneurons during weeks $2-4\left({ }^{*}\right.$ math $5^{-1-}$ : weeks $2-4$, $p<0.001)$. BE interneurons show fewer processes than WT at week 2 ( $\left.{ }^{*} p<0.001\right)$. C, WT interneurons display increased higher-order branching between weeks 1 and $3{ }^{*}$ week $2, p<$ 0.0001 ; week $3, p=0.029)$. math $5^{-1-}$ and BE interneurons display decreased complexity compared with WT (*math5 ${ }^{-1-}$ : week $2, p<0.001$; week $3, p=0.014$; week 4, $p=0.002$; BE: week $2, p=0.012) . D$, math $5^{-1-}$ and BE interneurons displayed smaller arbor field sizes ( ${ }^{*}$ math ${ }^{-l-}$ : week $2, p=0.006$; week $4, p=0.023 ; \mathrm{BE}$ : week $2, p=0.042$ ), and experience field retraction during week $4\left({ }^{*} p=0.022\right.$ ). For all analyses, WT: week $1, n=3$ mice, 10 cells; week 2, $n=7$ mice, 24 cells; week $3, n=4$ mice, 17 cells; week 4, $n=3$ mice, 14 cells; math5 ${ }^{-1-}$ : week $1, n=4$ mice, 12 cells; week $2, n=5$ mice, 24 cells; week $3, n=5$ mice, 18 cells; week $4, n=3$ mice, 12 cells; BE: week $2, n=4$ mice, 13 cells.

$0.013)$, displaying an approximately twofold change in area $(p=$ 0.026). After the second postnatal week, soma size stabilized. By contrast, math $5^{-1-}$ somata did not undergo an age-related change, remaining constant between weeks 1 and 4 (Fig. $3 A$, red; $\left.F_{(3,120)}=3.722 ; p=0.884\right)$. Comparisons with WT interneurons revealed that math $5^{-1-}$ interneuron somata were significantly smaller between weeks 2 and $4\left(F_{(1,120)}=36.54\right.$; week $2, p<$ 0.0001 ; week $3, p=0.0015$; week $4, p=0.0066$ ).

To assess the development of arbor architecture, we examined the total number of processes, the branch order, and the size of the arbor field (Fig. $3 B-D$ ). When considering these features, all branching elements (presumed axons and dendrites) were included in the analyses. WT interneurons undergo a number of 


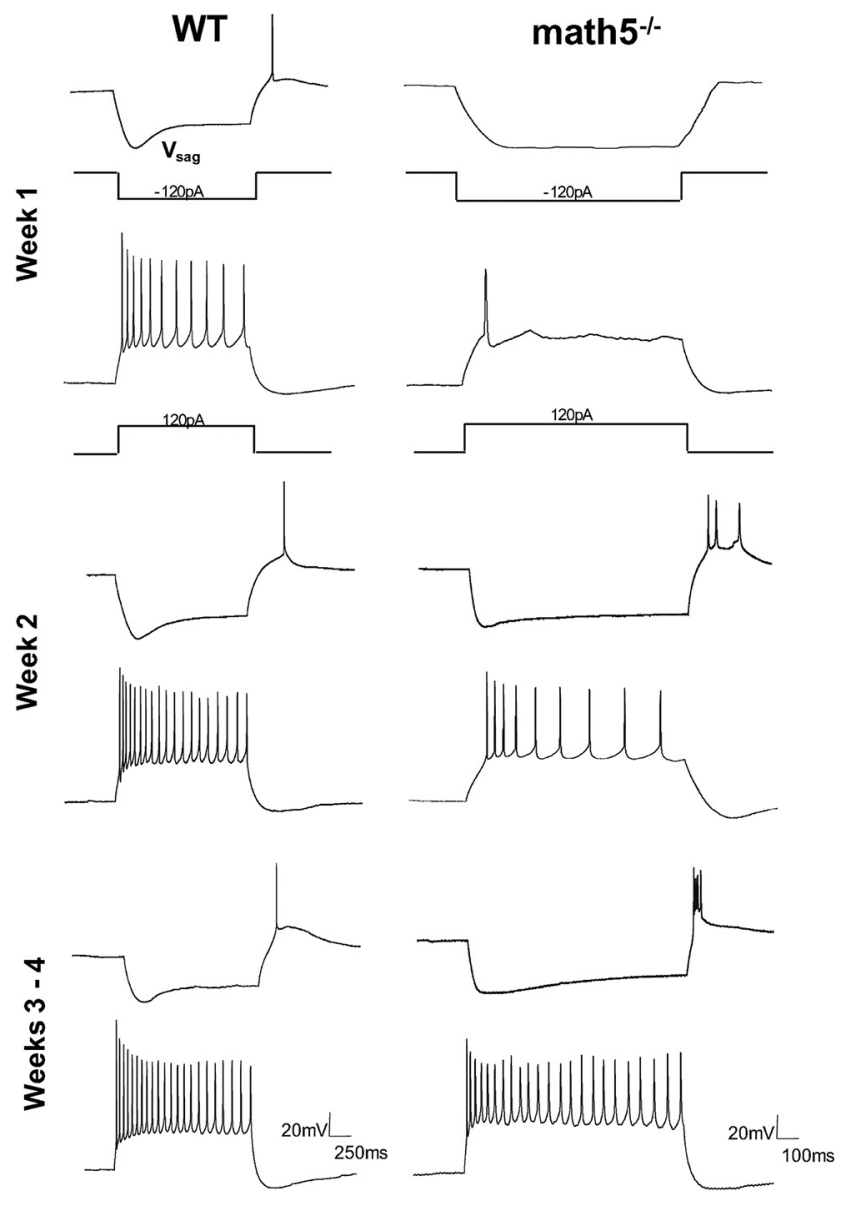

Figure 4. Intrinsic membrane properties of dLGN interneurons in WT and math5 ${ }^{-1-}$ interneurons. Examples of voltage responses to hyperpolarizing $(-120 \mathrm{pA})$ and depolarizing (150 pA) current step pulses from interneurons at different postnatal weeks (1-4) for WT (left) and math $5^{-I-}$ (right) interneurons; WT: RMP, -55 to $60 \mathrm{mV}$; math $5^{-I-}$ : RMP, -45 to 50 $\mathrm{mV}$. For WT mice, interneurons exhibit a strong $V_{\text {sag }}$ in response to hyperpolarizing pulses following the termination of the current pulse. Membrane depolarization evokes a train of action potentials. In math $5^{-1-}$ mice, interneuron responses remain relatively immature.

age-related changes in arbor architecture (Fig. $3 B-D$, black). For example, there was a significant increase in the total number of processes (Fig. $3 B ; F_{(3,122)}=18.65, p<0.0001$ ). Between weeks 1 and 2 , the total number of processes increased approximately threefold $(p<0.0001)$. However, this increase was transient, and following the second postnatal week the number of processes showed a significant decrease by nearly $40 \%(p<0.001)$. Despite this pruning, the number of arbors during week 4 was still 1.6fold greater than at week $1(p=0.003)$. These changes were accompanied by a significant increase in branch order (Fig. $3 C$; $\left.F_{(1,120)}=19.09, p<0.001\right)$. For instance, between weeks 1 and 2, branch order nearly doubled from fourth order to ninth order, with some cells exhibiting as high as 12 th order branching $(p<$ $0.001)$. WT branch order also decreased during weeks $2-3$, from ninth to sixth order $(p<0.001)$, and at week 4 it remained higher than at week $1(p=0.029)$. Finally, dLGN interneurons experienced a significant change in arbor field size (Fig. $3 D ; F_{(3,137)}=$ $3.307, p=0.012$ ). Between weeks 1 and 2, arbor volume doubled $(p=0.022)$ and then stabilized $(p=0.998)$. Overall, these data suggest that interneuron arbors undergo an exuberant branching phase between weeks 1 and 2, then prune back during week 3 when their architecture stabilizes to resemble their adult-like form.
A

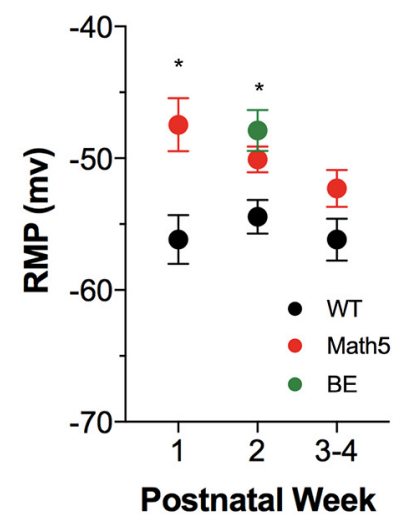

B
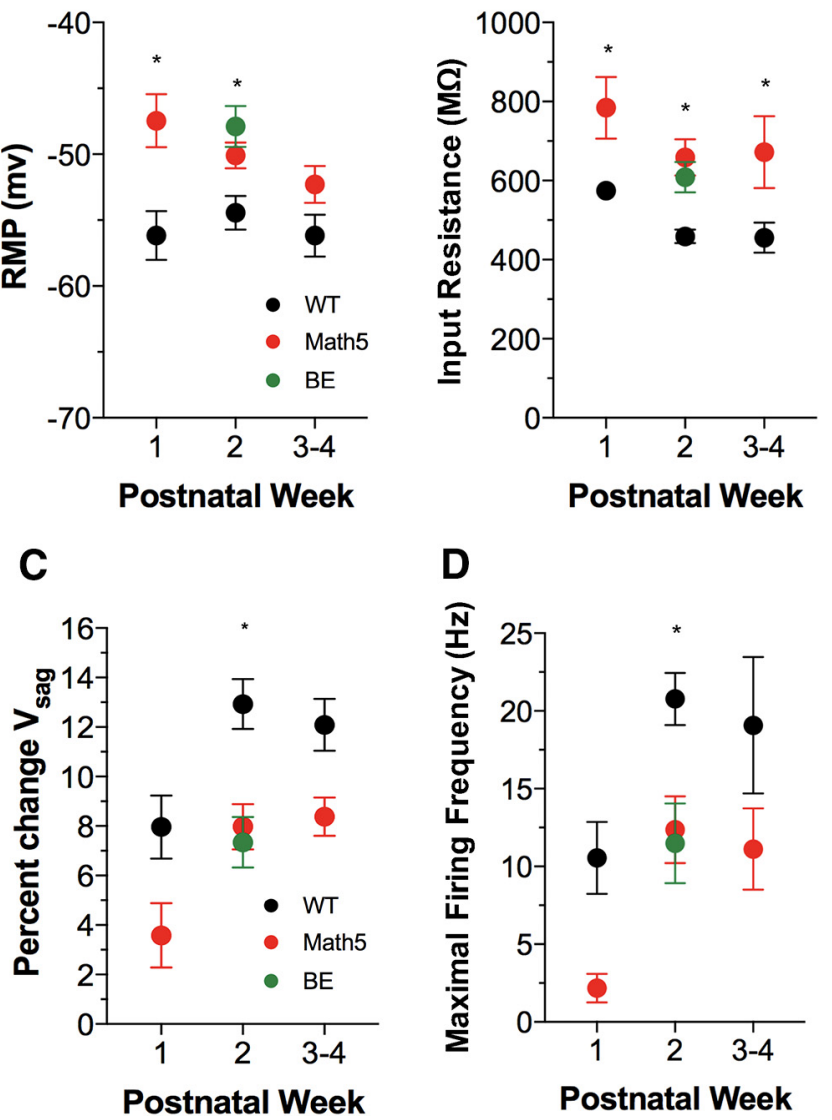

Figure 5. Passive and active membrane properties of dLGN interneurons in WT, math $5^{-1-}$, and $B E$ interneurons. $\boldsymbol{A}-\boldsymbol{D}$, Summary plots displaying age-related changes in resting membrane potential $(\boldsymbol{A})$, input resistance $(\boldsymbol{B}), \mathrm{I}_{H}$ amplitude $(\boldsymbol{C})$, and firing frequency $(\boldsymbol{D})$ of interneurons in WT (black), math5 ${ }^{-1-}$ (red), and BE (green) mice. Each point represents mean values \pm SEM arranged by postnatal week. $A$, math $5^{-1-}$ and BE interneurons exhibit more depolarized RMPs than WT ( ${ }^{*}$ math5 ${ }^{-1-}$ : week 1, $p=0.003$; week 2, $p=0.035$; BE: week 2, $p=0.003)$. $B$, math $5^{-1-}$ and $B E$ interneurons have a higher input resistance than WT interneurons ( ${ }^{*}$ math5 ${ }^{-1-}$ : week $1, p=0.038$; week $2, p=0.013$; weeks $3-4, p=0.027$; BE: $p=0.042)$. C, WT interneurons show an increase in $V_{\text {sag }}$ between weeks 1 and $2\left({ }^{*} p=0.029\right)$, whereas math $^{-1-}$ and BE interneurons are decreased compared with WT interneurons $\left(^{*}\right.$ math $5^{-1-}$ : week $\left.2, p=0.002 ; \mathrm{BE}: p<0.001\right)$. D, In WT mice, interneurons experience a twofold increase in frequency between weeks 1 and $2\left({ }^{*} p=0.005\right)$. Between weeks 1 and 2 , math $5^{-1-}$ interneurons also show increases in frequency $\left({ }^{*} p=0.0006\right)$, but both math $5^{-1-}$ and BE interneurons remain lower compared with WT interneurons $\left({ }^{*}\right.$ math $5^{-1-}$ : week $2, p=0.015$; BE: week $2, p=0.009)$. The numbers of cells are the same as in Figure 3 .

Unlike WT interneurons, math $5^{-1-}$ interneurons failed to show many of these changes (Fig. $3 B, C$, red). The number of processes and branch complexity remained stable across age (total processes: $F_{(3,122)}=18.65, p=0.9666$; branch complexity: $\left.F_{(3,120)}=19.09, p=0.580\right)$, and after week 1 these features were significantly reduced compared with WT interneurons (total processes: $F_{(1,122)}=104.87, p<0.001$; branch complexity: $F_{(1,120)}$ $=83.17, p<0.001)$. Interestingly, math $5^{-/-}$interneurons undergo a 2.5-fold retraction in arbor field size between weeks 3 and $4(p=0.022)$ and were significantly smaller than WT interneurons (Fig. $3 D ; F_{(1,137)}=16.348$; week $2, p=0.006$; week $4, p=$ 0.023 ). A similar pattern was observed after early BE (Fig. 3, week 2; see Fig. 6). For example, at P14 ( $n=4$ mice), an age when math $5^{-l-}$ defects were most evident, interneurons in BE mice $(n=13)$ displayed many of the same morphological defects as math $5^{-1-}$ mice, having smaller soma (Fig. $3 A$; see Fig. $6 B$; WT vs BE: $F_{(2,56)}=12.51, p=0.0014$; math $5^{-1-}$ vs BE: $\left.p=0.890\right)$, 
A

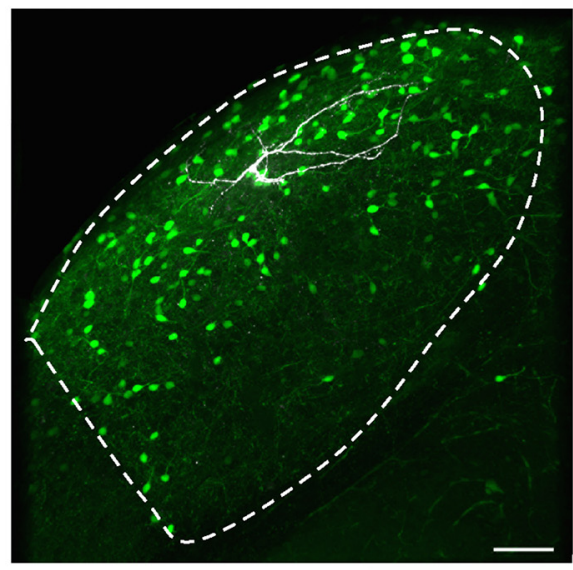

B

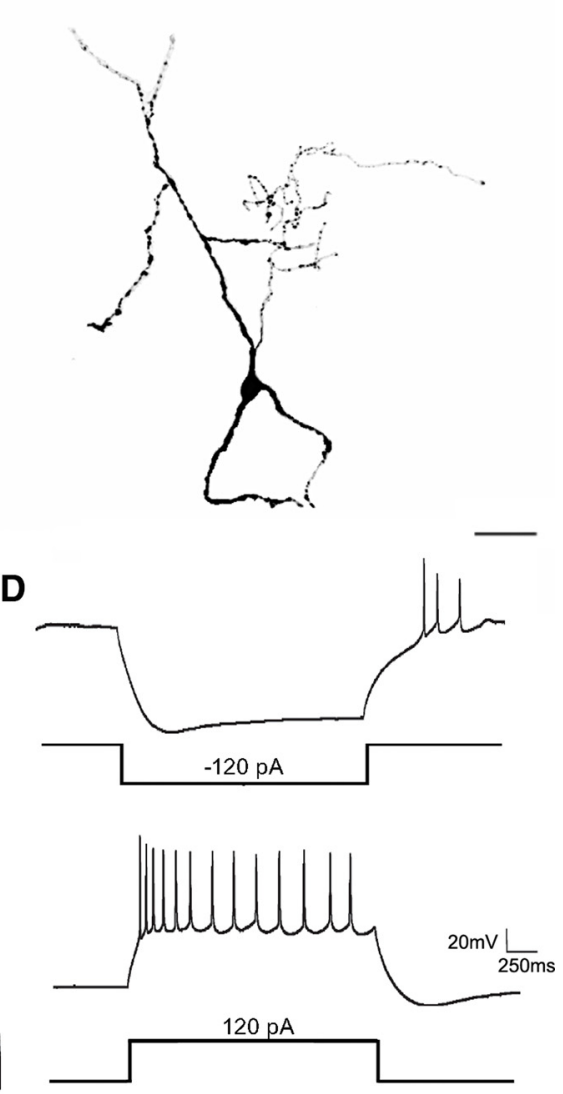

Figure 6. Form and function of interneurons in dLGN after early BE. $\boldsymbol{A}$, Coronal slice through dLGN of a P14 GAD67 WT mouse that had a binocular enucleation at P1.5. Example of GFP-expressing interneuron that was filled with biocytin during in vitro intracellular recording and used for 3-D reconstruction. Scale bar, $40 \mu \mathrm{m}$. BE, like math5 ${ }^{-1-}$, disrupts migration, and many GFP ${ }^{+}$ interneurons reside in the dorsolateral region of $\mathrm{dLGN}$. $\boldsymbol{B}$, A reconstruction of a biocytin-filled interneuron at P14. Scale bar, $50 \mu \mathrm{m}$. C, Record showing the sIPSC responses before and after bath application of $\mathrm{mGluR}_{5}$ agonist DHPG $(50 \mu \mathrm{M})$. Arrows depict the time of drug delivery. Inset depicts the corresponding frequency histograms and plots the number of inhibitory events as a function of time. The bin width is $30 \mathrm{~s}$. The activation of $\mathrm{mGluR}_{1,5}$ with $\mathrm{DHPG}$ has a negligible effect on activity. $\boldsymbol{D}$, Voltage responses to hyperpolarizing $(-120 \mathrm{pA})$ and depolarizing $(+150 \mathrm{pA})$ current step pulses.

fewer branches (Fig. $3 B$; see Fig. $6 B$; WT vs BE: $F_{(2,55)}=58.31$, $p=0.001$; math $5^{-1-}$ vs BE, $\left.p=0.0899\right)$, as well as a reduction in branch order (Fig. $3 C$; see Fig. $6 B$; WT vs BE: $F_{(2,54)}=27.42, p=$ 0.012 ; math $5^{-l-}$ vs BE, $p=0.845$ ), and arbor field size (Fig. $3 D$; see $6 B$; WT vs BE: $F_{(2,54)}=5.557, p=0.006$; math $5^{-1-}$ vs BE: $p=$ 0.789 ) than age-matched WT interneurons.

Thus, these results demonstrate that interneurons in math $5^{-1-}$ and BE mice fail to remodel and maintain a simple, sparse morphology throughout development. Moreover, the similarity between math $5^{-1-}$ and $\mathrm{BE}$ groups indicate that the absence of math 5 by itself does not contribute to the disruption in interneuron development.

\section{Intrinsic membrane properties of WT and math $5^{-/-}$interneurons}

To assess the development of intrinsic membrane properties, we evaluated RMP, input resistance, the hyperpolarization-activated $\mathrm{I}_{\mathrm{H}}$, and the frequency of spike firing frequency. Figure 4 provides representative examples of the voltage responses of interneurons evoked by square-wave hyperpolarizing (Fig. 4, top) and depolarizing (Fig. 4, bottom) current pulses for WT interneurons (P3$\mathrm{P} 30, n=68$ cells) and math5 ${ }^{-1-}$ interneurons (P4-P30, $n=75$ cells). Overall, neurons exhibited a relatively high membrane in- put resistance, which led to a strong voltage response to current injection. A prominent feature of interneurons is the presence of an inward rectification (i.e., depolarizing sag, $V_{\text {sag }}$ ) that occurs during membrane hyperpolarization, a response attributed to the activation of the $\mathrm{I}_{\mathrm{H}}$ (Williams et al., 1996; Seabrook et al., 2013b; Leist et al., 2016). Membrane depolarization also gave rise to a train of action potentials that showed little to no frequency accommodation. These properties were apparent in both WT and math $5^{-1-}$ interneurons and began to emerge between weeks 1 and 2.

Figure 5, $A$ and $B$, summarizes the agerelated changes in RMP and input resistance of dLGN interneurons. In WT interneurons, RMP and input resistance remained relatively stable with age, averaging $-56 \mathrm{mV}$ and $485 \mathrm{M} \Omega$, respectively (Fig. $5 A, B$, black: RMP: $F_{(1,137)}=1.132$, $p=0.854$; input resistance: $F_{(1,130)}=$ 2.178, $p=0.702)$. A similar pattern was apparent in math $5^{-1-}$ interneurons (Fig. $5 A, B$, red: RMP, $-50 \mathrm{mV}$; and input resistance, 660-670 M $\Omega$; RMP, $F_{(1,137)}=$ $1.132, p=0.259$; input resistance, $F_{(1,130)}$ $=2.178, p=0.472$ ). However, these values were different from those for WT interneurons. In math $5^{-1-}$ interneurons, RMPs were more depolarized between weeks 1 and 2 (Fig. $5 A ; F_{(1,137)}=18.01$; week $1, p=0.003$; week $2, p=0.035)$, and overall input resistance was higher at all ages (Fig. $5 B ; F_{(1,130)}=17.65$; all $p$ values $<0.038$ ), a result likely due to the their smaller soma size (Fig. $3 A$ ). We also examined $\mathrm{I}_{\mathrm{H}}$ by measuring the amplitude of the depolarizing sag as a percentage change from steady state $\left(V_{\text {sag }}\right)$. In WT mice, interneurons exhibited a 1.5-fold change between weeks 1 and 2 (Fig. 5C; $\left.F_{(2,127)}=5.648 ; p=0.044\right)$, and stabilized thereafter $(p=$ $0.589)$. Maximal spike firing to strong depolarizing current pulses $(-120-150 \mathrm{pA})$ showed a twofold increase between weeks 1 and 2 (Fig. $5 D ; F_{(2,138)}=8.254 ; p=0.037$ ), and then stabilized ( $p=0.607)$.

By contrast, in math5 ${ }^{-1-}$ interneurons, $\mathrm{I}_{\mathrm{H}}$ remained relatively stable with age (Fig. $5 C ; F_{(2,138)}=2.47, p=0.351$ ), along with a sixfold increase in spike firing between weeks 1 and 2 $\left(F_{(2,138)}=8.254, p=0.005\right)$. Compared with WT interneurons, math5 ${ }^{-1-}$ interneurons showed significantly lower values for $V_{\text {sag }}$ and maximal spike firing (Fig. $5 C, D ; I_{\mathrm{H}}, F_{(1,127)}=14.537$, $p<0.001$; firing frequency, $\left.F_{(1,138)}=14.764, p<0.001\right)$, due largely to the differences seen during week $2\left(\mathrm{I}_{\mathrm{H}}, p=0.002\right.$; firing frequency, $p=0.015$ ).

Interneurons recorded at P14 in BE mice displayed many of the same electrophysiological features as math $5^{-1-}$ interneurons, having a higher resting membrane potential (Fig. 5A; WT vs BE: $F_{(2,83)}=6.832, p=0.002$; math $5^{-l-}$ vs BE, $\left.p=0.255\right)$, and input resistance (Fig. $5 B$; WT vs BE: $F_{(2,77)}=5.592 ; p=0.042$; math $5^{-1-}$ vs BE, $p=0.984$ ), as well as a reduction in $V_{\text {sag }}$ (Fig. $5 C$; $6 D$; WT vs BE: $F_{(2,77)}=9.984, p=0.0002$; math $5^{-/-}$vs BE, 
$p=0.672$ ) and maximal firing frequency

(Figs. $5 D, 6 D$; WT vs BE: $F_{(2,83)}=6.830$, $p=0.009$; math $^{-1-}$ vs BE, $p=0.789$ ) than age-matched WT interneurons. Thus, these results reveal that math $5^{-1-}$ and $\mathrm{BE}$ interneurons remain functionally immature.

Synaptic connectivity between dLGN interneurons and relay neurons in WT and math $5^{-1-}$ mice

To study the synaptic connectivity between interneurons and relay cells, we measured the frequency and amplitude of IPSCs in relay neurons that were pharmacologically evoked by the activation of F2 terminals. These processes express the Group I $\mathrm{mGluR}_{1,5}$, and the bath application of the agonist DHPG evokes F2mediated $\mathrm{GABA}_{\mathrm{A}}$ receptor-mediated inhibition onto relay neurons (Cox et al., 1998; Cox and Sherman, 2000; Govindaiah and Cox, 2006). Figure 7 shows examples of biocytin-filled relay cells in WT (Fig. 7A) and math5 ${ }^{-1-}$ (Fig. 7B) along with their corresponding IPSC activity (5 min) recorded before, during, and after DHPG application. As summarized in Figure $8, A$ and $B$, during predrug conditions there were no differences in IPSC activity between WT and math $5^{-1-}$ interneurons (frequency: $F_{(1,54)}=35.03$; $p=0.950$; amplitude: $F_{(1,54)}=0.623, p=$ $0.106)$. However, WT neurons (P14 to P25: $n=22$ cells, $n=59,061$ IPSCs) showed a significant increase in IPSC frequency and amplitude following DHPG treatment that persisted for several seconds (120-420 s; Fig. 8A, frequency: $F_{(1,54)}=35.03, p<0.0001$; Fig. $8 B$, amplitude: $\left.F_{(1,54)}=0.623, p=0.0004\right)$. IPSC frequency more than doubled with amplitude showing a 1.3-fold change after agonist application. In math $5^{-1-}$ neurons, relay cells (P14-P25: $n=33$ cells, $n=$ 50,676 IPSCs) showed a modest increase in IPSC frequency (Fig. $8 A ; F_{(1,54)}=$ $35.03, p=0.018)$ and no change in amplitude (Fig. $\left.8 B ; F_{(1,54)}=0.623, p=0.995\right)$ following DHPG application. Moreover, postdrug math $5^{-1-}$ IPSC frequency as well as amplitude were significantly lower than WT $(p<0.0001)$.

To demonstrate the differences in magnitude of the DHPGevoked increase in IPSCs between the two groups, for each neuron we calculated the percentage change in IPSC frequency (Fig. $8 A$, right) and amplitude (Fig. $8 B$, right). Overall, WT relay neurons displayed far greater changes [frequency: mean $156.231 \%$; 95\% confidence interval (CI), 96-306\%; amplitude: mean, $31.814 \%$; 95\% CI, -23-200\%], showing significantly higher values than math $5^{-1-}$ relay neurons (frequency: mean, $17.523 \%$; 95\% CI, $-21 \%$ to $93 \%$; amplitude: mean, $2.023 \%$; $95 \% \mathrm{CI}$, $-23 \%$ to $49 \%$; Mann-Whitney rank sum test, $p<0.0001$ ). in math $5^{-l-}$ mice.
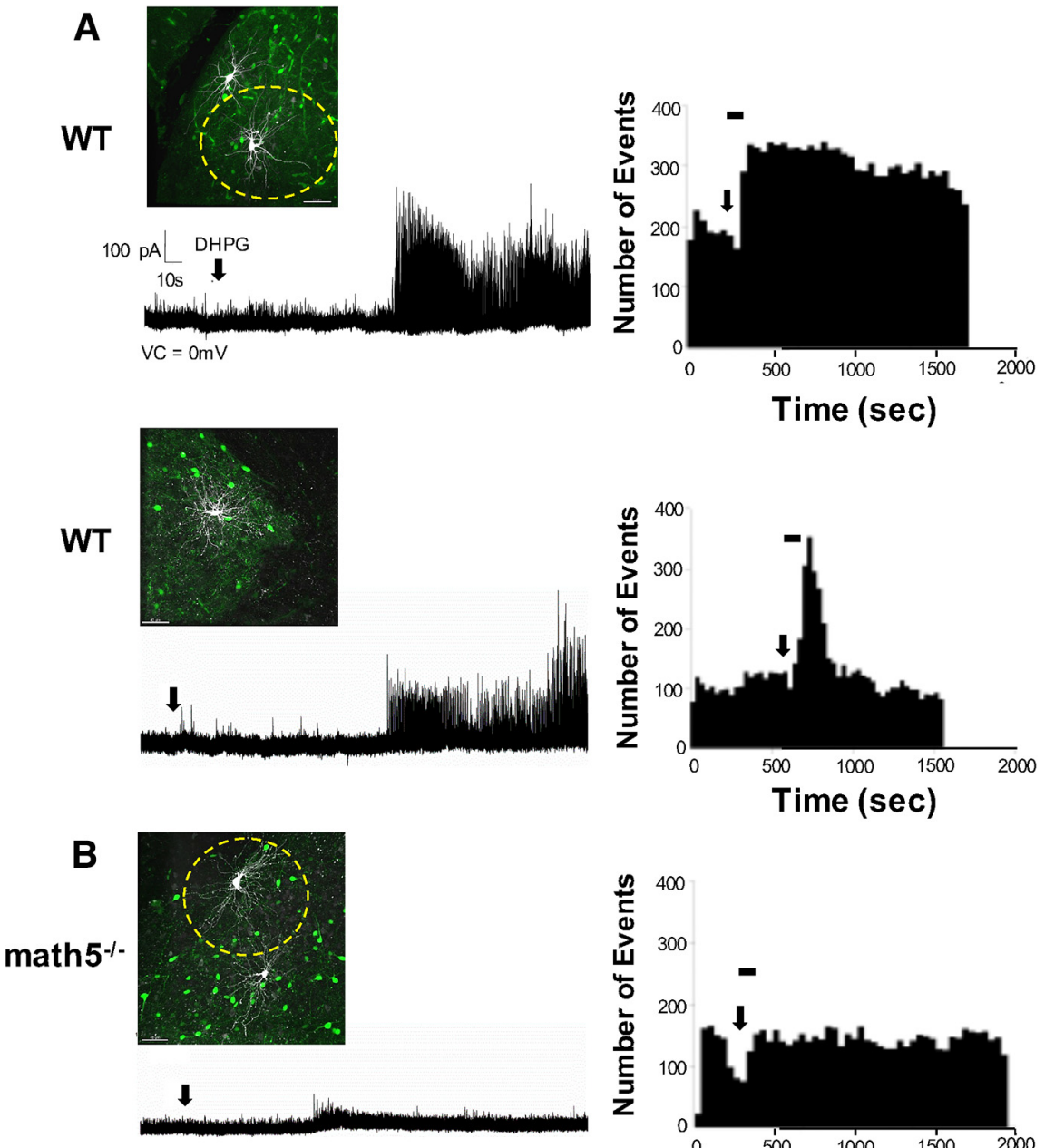

Figure 7. Pattern of spontaneous inhibitory activity in relay neurons in WT and math $5^{-1-}$ mice. $A, B$, Examples of WT $(\boldsymbol{A})$ and math5 $5^{-l-}(\boldsymbol{B}) \mathrm{dLGN}$ relay neurons (scale bar, $40 \mu \mathrm{m}$ ) and their corresponding sIPSC responses before and after bath application of the $\mathrm{mGluR}_{5}$ agonist DHPG $(50 \mu \mathrm{M})$. Black horizontal bars above histograms reflect post-drug analysis period. All other conventions are the same as in Figure 6. DHPG application leads to a sustained increase in IPSC activity in WT mice and little or no change
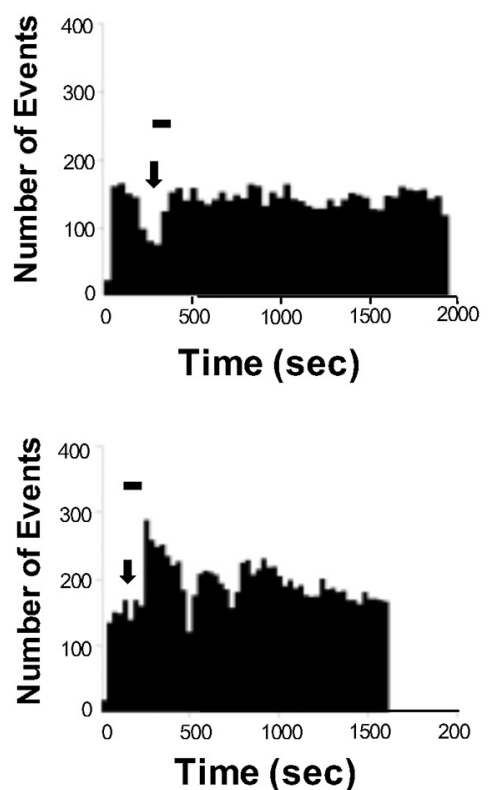

Similar to math $5^{-/-}$relay neurons, after BE, interneurons $(n=11)$ showed little or no change in IPSC frequency or amplitude after DHPG application (Figs. 6C, 8; predrug vs postdrug frequency: $F_{(1,64)}=210.3, p=0.196$; predrug vs postdrug amplitude: $\left.F_{(1,64)}=164.4, p=0.204\right)$. While predrug activity was similar to WT and math $5^{-1-}$ (predrug frequency: $F_{(2,64)}=18.25$, $p=0.055$; predrug amplitude: $\left.F_{(2,64)}=0.690, p=0.504\right)$, postdrug values were significantly lower than WT (Fig. 8; WT vs BE: frequency, $F_{(2,64)}=18.25, p<0.0001$; amplitude, $p<0.001$ ), showing little change between predrug and postdrug conditions 

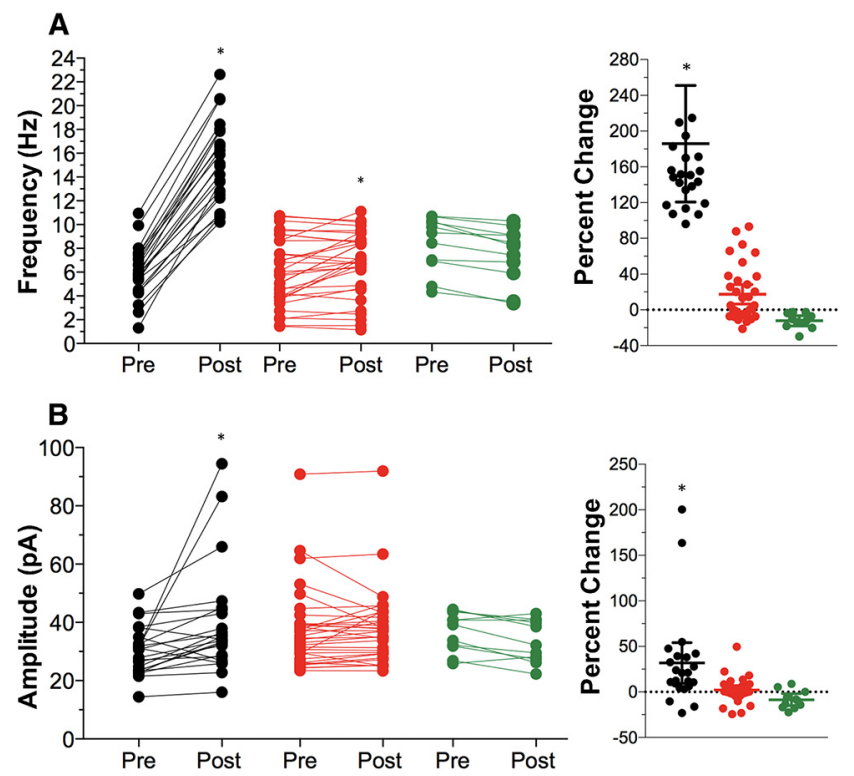

Figure 8. $\quad A, B, I P S C$ frequency and amplitude response before and after $m G$ luR5 activation in WT, math $5^{-l-}$, and BE relay neurons. $A$, Left, Scatter plot showing DHPG-induced changes in IPSC frequency for WT (black), math $5^{-1-}$ (red), and BE (green) relay neurons. Solid lines and dots depict predrug and post-DHPG measurements from individual relay neurons (WT, $n=23$; math $\left.5^{-l-}, n=33\right)$. WT cells display higher post-DHPG frequencies compared with math $5^{-l-}$ cells $\left({ }^{*} p<0.0001\right)$ and BE cells $\left({ }^{*} p<0.001\right)$. Right, Scatter plot illustrating the percentage change in frequency for each relay cell in WT, math $5^{-1-}$, and BE cells. Horizontal bars are the means and $95 \%$ confidence intervals. $B$, Left, Scatter plots showing the DHPGinduced changes in IPSC amplitude. Only WT relay neurons showed an increase $\left({ }^{*} p=0.0004\right)$. Right, Summary plot of drug effect expressed as the percentage change. WT cells showed increased amplitude percentage change compared with math $5^{-1-}$ cells $\left(^{*} p=0.0002\right)$ and BE cells $\left({ }^{*} p=0.003\right)$.

(frequency: mean, $-12.25 \%$; $95 \% \mathrm{CI},-30 \%$ to $0 \%$; amplitude: mean $-8.531 \%$; $95 \%$ CI, $-23 \%$ to $9 \%$ ), yet significantly lower than WT (Fig. 8; one-way ANOVA, frequency: $F_{(2,64)}=28.57$, $p<0.001$; amplitude: $\left.F_{(2,64)}=8.222, p=0.003\right)$. Consistent with our earlier findings, $\mathrm{BE}$ relay neurons showed similar percentage changes in activity as math $5^{-1-}$ (Fig. $8 A$, frequency, $p=0.351$; Fig. $8 B$, amplitude, $p=0.346$ ).

Together, these data suggest that the absence of retinal signaling disrupts the synaptic connectivity between intrinsic interneurons and relay neurons.

\section{Discussion}

A number of studies in mice describe how and when interneurons migrate to dLGN and make feedforward inhibitory connections with relay neurons (Bickford et al., 2010; Seabrook et al., 2013b; Golding et al., 2014; Jager et al., 2016). Here, we provide additional details about their morphological growth and the emergence of adult-like membrane properties to present a comprehensive time line of interneuron development (see Fig. 10 , top). In addition, our experiments in math $5^{-1-}$ mutants reveal that many of these features require retinal signaling (see Fig. 10, bottom).

At perinatal ages, interneurons begin to migrate to dLGN, and become evenly dispersed throughout the nucleus by the end of the first postnatal week (see Fig. 10, migration; Golding et al., 2014; Jager et al., 2016). Once migration is complete, arbor elaboration and remodeling begins. By the second postnatal week, the number of processes, arbor complexity, and arbor field size exhibit substantial increases (see Fig. 10, exuberant branching and arbor field growth). During this time, intrinsic membrane prop-
A
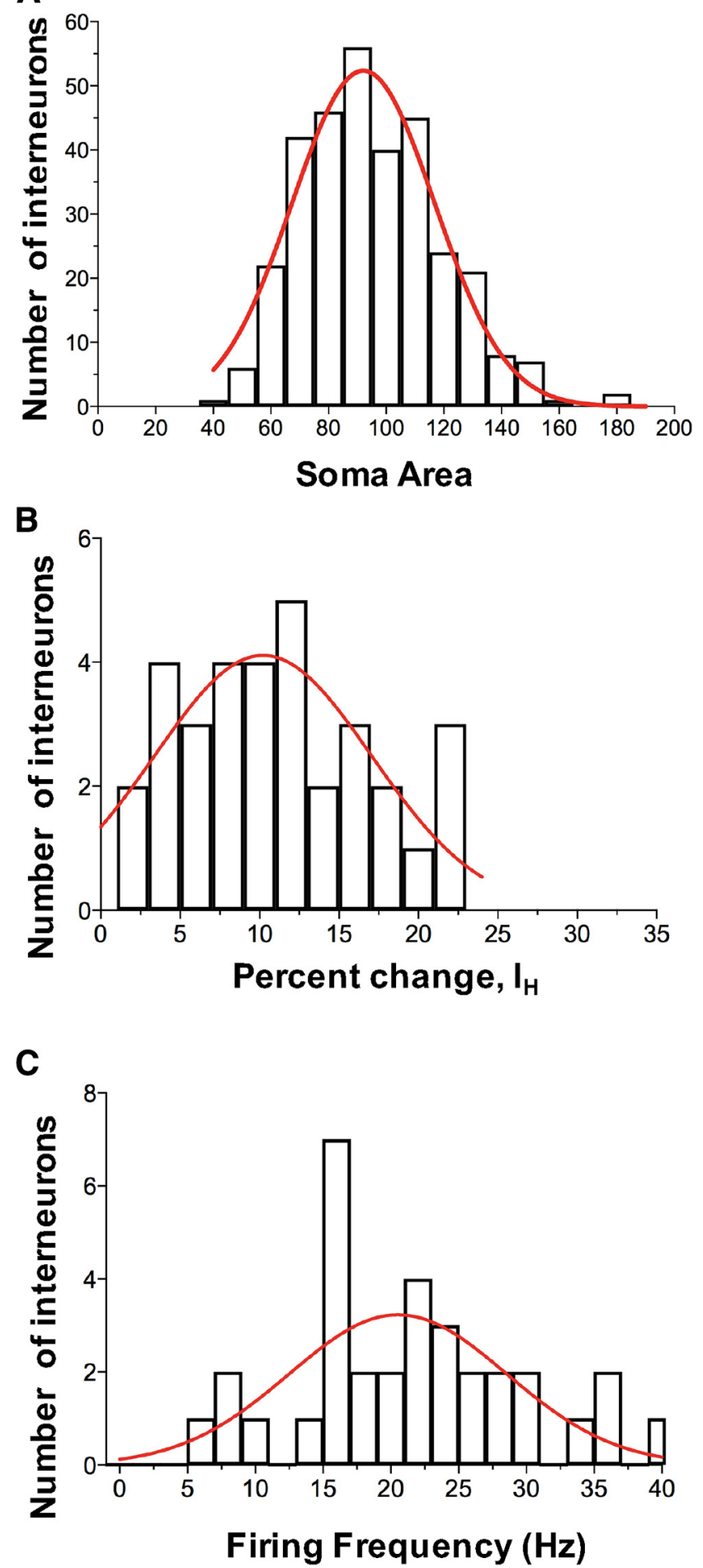

Figure 9. Frequency distribution of soma size, $V_{\text {sag }}$ and spike firing of WT interneurons. $\boldsymbol{A}-\boldsymbol{C}$, Frequency distribution of interneuron soma area $(\boldsymbol{A}), V_{\text {sag }}(\boldsymbol{B})$, and firing frequency $(\boldsymbol{C})$. Red lines represent single Gaussian fits generated from nonlinear regression analysis (soma size: $\mu=92.08, \sigma=24.71 ; V_{\text {sag }}: \mu=10.22, \sigma=6.831$; firing frequency: $\mu=12.63, \sigma=$ 17.56). $A$, Soma area measured from GFP ${ }^{+}$interneurons in coronal slices of dLGN at weeks $2-4$, when the area stabilized (weeks $2-4, n=3$ mice, 3 sections/mouse). $\boldsymbol{B}$, Values for the percentage change in $V_{\text {sag }}$ taken from weeks $2-4$. C, Values for firing frequency taken from weeks $2-4$. 
erties are maturing, as $\mathrm{I}_{\mathrm{H}}\left(V_{\text {sag }}\right)$ and firing frequency reach peak values (see Fig. 10, maturation of membrane properties). Interestingly, this phase of exuberant growth is followed by a brief period of arbor pruning in week 3 , where the number of processes and complexity decrease (see Fig. 10, branch pruning). By week 4, the arbor architecture stabilizes and interneurons assume a stereotypic, class 3 morphology (see Fig. 10, branch and field stabilization). Moreover, during the active period of arbor remodeling (see Fig. 10, exuberant branching and branch pruning), feedforward inhibitory synapses emerge (see Fig. 10, synapse formation and connectivity; Bickford et al., 2010).

According to a recent report (Leist et al., 2016), dLGN interneurons are composed of two classes based on soma diameter, with smaller ones having a higher density of $\mathrm{I}_{\mathrm{H}}$ channels and higher rates of firing compared with larger ones. However, in our study we failed to find such distinctions. For example, in WT soma area (in square micrometers) measurements of interneurons were normally distributed and best fit by a single Gaussian function. Similar relationships were found for the amplitude of $\mathrm{I}_{\mathrm{H}} V_{\text {sag }}$ and spike firing frequency (Fig. 9). The reasons for such a discrepancy remain unclear but may be related to differences in the measurement of soma size, the primary distinguishing factor (e.g., 3-D area vs 2-D diameter).

Our results in math $5^{-/-}$mice reveal that the absence of retinal innervation disrupts many aspects of interneuron development (Fig. 10, bottom). Consistent with other reports, the elimination of retinal signaling leads to abnormal clustering of interneurons, and a failure to distribute evenly throughout dLGN (Fig. 10, disrupted migration; Golding et al., 2014). Additionally, based on our 3-D reconstructions, math5 $5^{-1-}$ interneurons do not undergo arbor remodeling during postnatal development. Instead, they maintain simple, sparse arbors at all ages (Fig. 10, arrested arbor branching). The size of their arbor field is also restricted (Fig. 10, dystrophic arbor field growth), and during the fourth postnatal week fields actually retract (Fig. 10, field retraction). Functionally, the intrinsic membrane properties of math5 ${ }^{-1-}$ interneurons fail to mature, and exhibit decreased spike firing rates and weaker $V_{\text {sag }}$ (Fig. 10, decreased firing frequency and $I_{\mathrm{H}}$ ). Furthermore, the elimination of retinal signaling also leads to a disruption in feedforward inhibition. Recordings in math $5^{-1-}$ relay cells show little change in IPSC frequency after pharmacological activation of F2 terminals. By contrast, WT relay neurons exhibit a twofold to fourfold increase in IPSC frequency (Cox and Sherman, 2000; Govindaiah and Cox, 2006). These findings sugsynaptic connectivity.
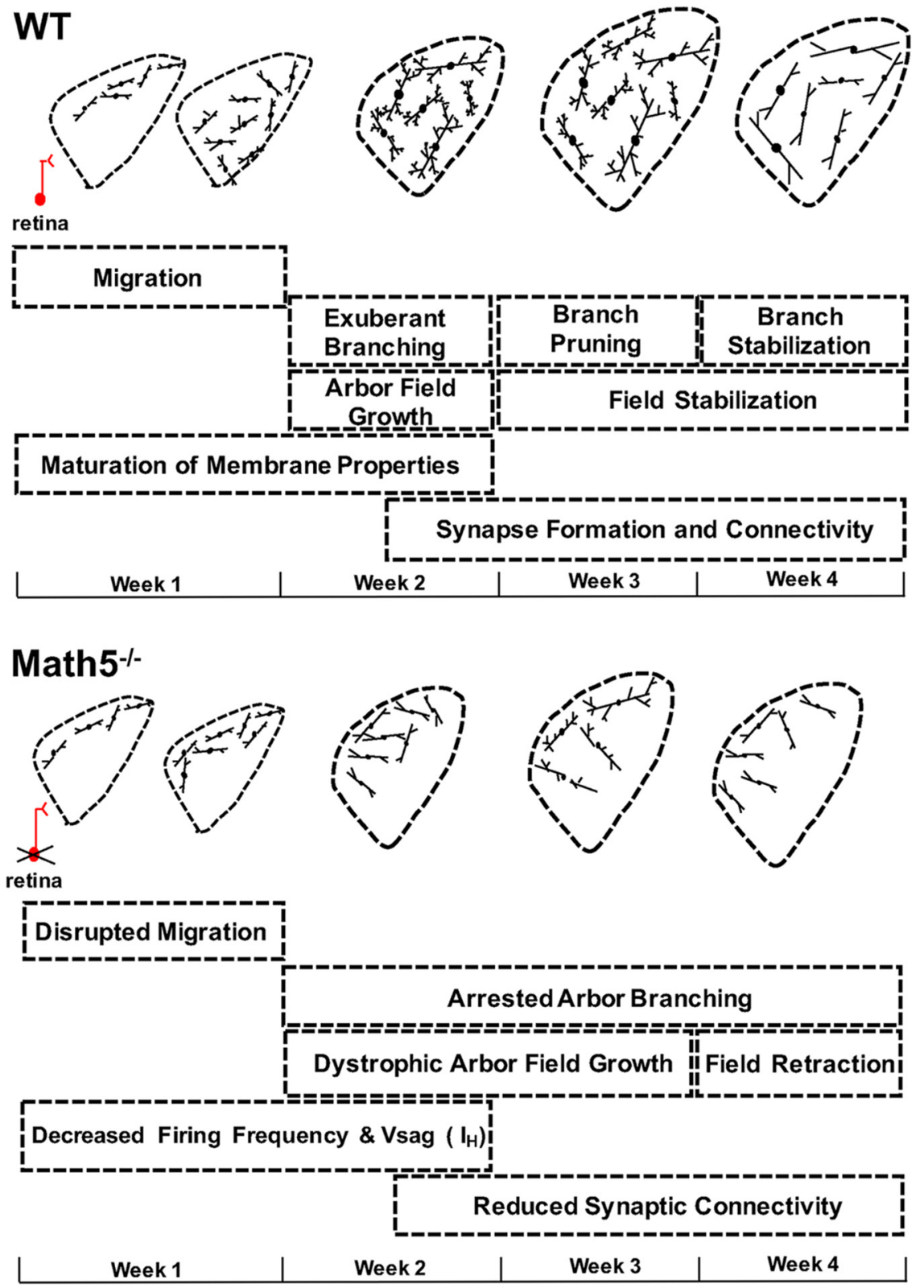

Figure 10. Development of interneurons in WT and math $5^{-1-}$ mice. Schematic summarizing the time line of WT (top) and math $^{-1-}$ (bottom) interneuron development. Boxes indicate various WT milestones: migration (Golding et al., 2014), arbor remodeling (i.e., exuberant branching, pruning, and stabilization), arbor field growth and stabilization, maturation of membrane properties, and synapse formation and connectivity. For math $5^{-1-}$ mice, the absence of retinal signaling results in disrupted migration, arrested arbor branching, dystrophic arbor field growth, decreased firing frequency $/ V_{\text {sag }}$, and reduced patterns of

gest that math $5^{-1-}$ relay cells contain fewer and/or weaker inhibitory synapses (Fig. 10, reduced synaptic connectivity). These results are consistent with previous studies that use early postnatal elimination of retinal signaling (Golding et al., 2014). However, the utility of a genetic form of deafferentation (i.e., math $5^{-1-}$ ) rules out the possibility that these disruptions were brought about by trauma or degeneration. Instead, they are likely a consequence of stunted arbor growth or the abnormal clustering of interneurons that occurs after the removal of retinal innervation. Interestingly, WT and math $5^{-1-}$ relay neurons display similar baseline IPSC activity, suggesting inhibitory input from extrinsic sources (e.g., pretectum, thalamic reticular nucleus) are intact and may act to compensate for the loss of intrinsic inhibi- 
tion. Such compensatory activity may reflect a form of homeostatic plasticity designed to maintain proper excitatory/ inhibitory balance (Turrigiano and Nelson, 2004; Maffei et al., 2006).

The current study elucidates the importance of retinal signaling, and its role in supporting the morphological development and emergence of feedforward inhibitory connections in dLGN. These findings are consistent with those of previous studies from our laboratory demonstrating that retinal input provides vital trophic support for the morphological development of dLGN relay cells (El-Danaf et al., 2015). Furthermore, our results imply that retinal signaling has a greater impact on interneurons than on relay cells. Although math $5^{-1-}$ relay neurons experience dystrophic dendritic growth, they retain relatively complex dendritic architecture, cell-class identity, and the full complement of voltage-gated membrane properties (El-Danaf et al., 2015). By contrast, dLGN interneurons in math $5^{-1-}$ mice fail to remodel, and instead remain morphologically and functionally immature.

It is important to consider that the removal of retinal input in dLGN could affect the activity of other local circuits involving interneurons and, thus, contribute indirectly to the disruptions we observed. For example, a potential influence could arise from collaterals of relay cells, which in the cat have been shown to provide excitatory input onto interneurons (Cox et al., 2003; Bickford et al., 2008). However, the existence of such a circuit in the mouse remains an open question. Moreover, the intrinsic membrane properties and spike firing of relay cells remain largely unaffected in math $5^{-1-}$ mice (El-Danaf et al., 2015), suggesting that any potential impact on interneurons from relay cells would be minimal. Interneurons also receive excitatory input from layer VI of visual cortex (Jurgens et al., 2012). While corticothalamic innervation of dLGN is accelerated in math $5^{-1-}$ mice, the strength and timing of synapse formation with dLGN neurons remains unaffected (Seabrook et al., 2013a), and occurs after the onset of the disruptions we observed.

While it is evident that retinal axons provide some form of trophic support for interneurons, the underlying molecular mechanism remains unknown. One possible candidate is BDNF, a neurotrophic factor implicated in the growth and elaboration of developing retinofugal circuits (Cohen-Cory and Fraser, 1995; Marshak et al., 2007; Cohen-Cory et al., 2010). BDNF is synthesized in RGCs and released by retinal axons, where it binds to receptor tyrosine kinase located on the dendrites of relay cells and interneurons (Avwenagha et al., 2006). Another intriguing candidate is fibroblast growth factor 15 (FGF15), a signaling molecule involved in widespread developmental processes including GABAergic differentiation, cell survival, and synapse formation (Hagemann and Scholpp, 2012, Martinez-Ferre et al., 2016). At perinatal ages, FGF15 is expressed along the presumed migratory path of interneurons, including the ventricular layer of the third ventricle, ventral LGN and dLGN (Gimeno et al., 2003). More importantly, developing RGCs express FGF15 at perinatal ages during the time when retinal axons innervate dLGN (Kurose et al., 2004).

Finally, a question that still remains is whether the defects in interneuron development noted here are brought about by a loss of retinal activity. While activity has proven vital for the developmental remodeling of sensory connections (Goodman and Shatz, 1993; Huberman et al., 2008), it can also influence early events such as axonal targeting and initial synapse formation (Catalano and Shatz, 1998; Anderson and Price, 2002; Hanson and Landmesser, 2004, 2006; Mizuno et al., 2007; Salcedo et al., 2011).
Indeed, blocking or altering early retinal activity disrupts some aspects of interneuron migration and circuit assembly in dLGN (Golding et al., 2014). However, whether the defects associated with math $5^{-1-}$ were brought about by the interruption of activity per se or by the disruption of a molecular/trophic cue that relies on retinal signaling (Cohen-Cory and Lom, 2004; Cheng et al., 2011; Park and Poo, 2013) remains to be tested. Overall, these studies provide an in-depth analysis of dLGN interneuron development and underscore the importance of retinal signaling in the developmental remodeling of their arbors and feedforward inhibitory synapse formation.

\section{References}

Anderson G, Price DJ (2002) Layer-specific thalamocortical innervation in organotypic cultures is prevented by substances that alter neural activity. Eur J Neurosci 16:345-349.

Avwenagha O, Bird MM, Lieberman AR, Yan Q, Campbell G (2006) Patterns of expression of brain-derived neurotrophic factor and tyrosine kinase B mRNAs and distribution and ultrastructural localization of their proteins in the visual pathway of the adult rat. Neuroscience 140:913-928.

Bickford ME, Wei H, Eisenback MA, Chomsung RD, Slusarczyk AS, Dankowsi AB (2008) Synaptic organization of thalamocortical axon collaterals in the perigeniculate nucleus and dorsal lateral geniculate nucleus. J Comp Neurol 508:264-285.

Bickford ME, Slusarczyk A, Dilger EK, Krahe TE, Kucuk C, Guido W (2010) Synaptic development of the mouse dorsal lateral geniculate nucleus. J Comp Neurol 518:622-635.

Brown NL, Kanekar S, Vetter ML, Tucker PK, Gemza DL, Glaser T (1998) Math5 encodes a murine basic helix-loop-helix transcription factor expressed during early stages of retinal neurogenesis. Development 125 : 4821-4833.

Brown NL, Patel S, Brzezinski J, Glaser T (2001) Math5 is required for retinal ganglion cell and optic nerve formation. Development 128:24972508.

Brzezinski JA 4th, Brown NL, Tanikawa A, Bush RA, Sieving PA, Vitaterna MH, Takahashi JS, Glaser T (2005) Loss of circadian photoentrainment and abnormal retinal electrophysiology in Math5 mutant mice. Invest Ophthalmol Vis Sci 46:2540-2551.

Catalano SM, Shatz CJ (1998) Activity-dependent cortical target selection by thalamic axons. Science 281:559-562.

Cheadle L, Tzeng CP, Kalish BT, Harmin DA, Rivera S, Ling E, Nagy MA, Hrvatin S, Hu L, Stroud H, Burkly LC, Chen C, Greenberg ME (2018) Visual experience-dependent expression of Fn14 is required for retinogeniculate refinement. Neuron 99:525-539.e10.

Chen C, Regehr WG (2000) Developmental remodeling of the retinogeniculate synapse. Neuron 28:955-966.

Cheng PL, Song AH, Wong YH, Wang S, Zhang X, Poo MM (2011) Selfamplifying autocrine actions of BDNF in axon development. Proc Natl Acad Sci U S A 108:18430-18435.

Cohen-Cory S, Fraser SE (1995) Effects of brain-derived neurotrophic factor on optic axon branching and remodelling in vivo. Nature 378:192196.

Cohen-Cory S, Lom B (2004) Neurotrophic regulation of retinal ganglion cell synaptic connectivity: from axons and dendrites to synapses. Int J Dev Biol 48:947-956.

Cohen-Cory S, Kidane AH, Shirkey NJ, Marshak S (2010) Brain-derived neurotrophic factor and the development of structural neuronal connectivity. Dev Neurobiol 70:271-288.

Cox CL, Sherman SM (2000) Control of dendritic outputs of inhibitory interneurons in the lateral geniculate nucleus. Neuron 27:597-610.

Cox CL, Reichova I, Sherman SM (2003) Functional synaptic contacts by intranuclear axon collaterals of thalamic relay neurons. J Neurosci 23: $7642-7646$.

Cox CL, Zhou Q, Sherman SM (1998) Glutamate locally activates dendritic outputs of thalamic interneurons. Nature 394:478-482.

Cullen MJ, Kaiserman-Abramof IR (1976) Cytological organization of the dorsal lateral geniculate nuclei in mutant anophthalmic and postnatally enucleated mice. J Neurocytol 5:407-424.

El-Danaf RN, Krahe TE, Dilger EK, Bickford ME, Fox MA, Guido W (2015) Developmental remodeling of relay cells in the dorsal lateral geniculate nucleus in the absence of retinal input. Neural Dev 10:19. 
Evangelio M, García-Amado M, Clascá F (2018) Thalamocortical projection neuron and interneuron numbers in the visual thalamic nuclei of the adult C57BL/6 mouse. Front Neuroanat 12:27.

Gimeno L, Brûlet P, Martínez S (2003) Study of Fgf15 gene expression in developing mouse brain. Gene Expr Patterns 3:473-481.

Golding B, Pouchelon G, Bellone C, Murthy S, Di Nardo AA, Govindan S, Ogawa M, Shimogori T, Lüscher C, Dayer A, Jabaudon D (2014) Retinal input directs the recruitment of inhibitory interneurons into thalamic visual circuits. Neuron 81:1443.

Goodman CS, Shatz CJ (1993) Developmental mechanisms that generate precise patterns of neuronal connectivity. Cell 72 Suppl:77-98.

Govindaiah G, Cox CL (2006) Metabotropic glutamate receptors differentially regulate GABAergic inhibition in thalamus. J Neurosci 26:13443-13453.

Guido W (2018) Development, form, and function of the mouse visual thalamus. J Neurophysiol 120:211-225.

Guillery RW (1966) A study of golgi preparations from the dorsal lateral geniculate nucleus of the adult cat. J Comp Neurol 128:21-50.

Hagemann AI, Scholpp S (2012) The tale of the three brothers- shh, Wnt, and Fgf during development of the thalamus. Front Neurosci 6:76.

Hammer S, Carrillo GL, Govindaiah G, Monavarfeshani A, Bircher JS, Su J, Guido W, Fox MA (2014) Nuclei-specific differences in nerve terminal distribution, morphology, and development in mouse visual thalamus. Neural Dev 9:16.

Hamos JE, Van Horn SC, Raczkowski D, Uhlrich DJ, Sherman SM (1985) Synaptic connectivity of a local circuit neurone in lateral geniculate nucleus of the cat. Nature 317:618-621.

Hanson MG, Landmesser LT (2004) Normal patterns of spontaneous activity are required for correct motor axon guidance and the expression of specific guidance molecules. Neuron 43:687-701.

Hanson MG, Landmesser LT (2006) Increasing the frequency of spontaneous rhythmic activity disrupts pool-specific axon fasciculation and pathfinding of embryonic spinal motoneurons. J Neurosci 26:12769-12780.

Hirsch JA, Wang X, Sommer FT, Martinez LM (2015) How inhibitory circuits in the thalamus serve vision. Annu Rev Neurosci 38:309-329.

Hong YK, Chen C (2011) Wiring and rewiring of the retinogeniculate synapse. Curr Opin Neurobiol 21:228-237.

Hooks BM, Chen C (2006) Distinct roles for spontaneous and visual activity in remodeling of the retinogeniculate synapse. Neuron 52:281-291.

Huberman AD, Feller MB, Chapman B (2008) Mechanisms underlying development of visual maps and receptive fields. Annu Rev Neurosci 31:479-509.

Jager P, Ye Z, Yu X, Zagoraiou L, Prekop HT, Partanen J, Jessell TM, Wisden W, Brickley SG, Delogu A (2016) Tectal-derived interneurons contribute to phasic and tonic inhibition in the visual thalamus. Nat Commun 7:13579.

Jaubert-Miazza L, Green E, Lo FS, Bui K, Mills J, Guido W (2005) Structural and functional composition of the developing retinogeniculate pathway in the mouse. Vis Neurosci 22:661-676.

Jurgens CW, Bell KA, McQuiston AR, Guido W (2012) Optogenetic stimulation of the corticothalamic pathway affects relay cells and GABAergic neurons differently in the mouse visual thalamus. PLoS One 7:e45717.

Krahe TE, El-Danaf RN, Dilger EK, Henderson SC, Guido W (2011) Morphologically distinct classes of relay cells exhibit regional preferences in the dorsal lateral geniculate nucleus of the mouse. J Neurosci 31: 17437-17448.

Kurose H, Bito T, Adachi T, Shimizu M, Noji S, Ohuchi H (2004) Expression of fibroblast growth factor 19 (Fgf19) during chicken embryogenesis and eye development, compared with Fgf15 expression in the mouse. Gene Expr Patterns 4:687-693.

Leist M, Datunashvilli M, Kanyshkova T, Zobeiri M, Aissaoui A, Cerina M, Romanelli MN, Pape HC, Budde T (2016) Two types of interneurons in the mouse lateral geniculate nucleus are characterized by different h-current density. Sci Rep 6:24904.
Lieberman AR (1973) Neurons with presynaptic perikarya and presynaptic dendrites in the rat lateral geniculate nucleus. Brain Res 59:35-59.

Maffei A, Nataraj K, Nelson SB, Turrigiano GG (2006) Potentiation of cortical inhibition by visual deprivation. Nature 443:81-84.

Marshak S, Nikolakopoulou AM, Dirks R, Martens GJ, Cohen-Cory S (2007) Cell autonomous TrkB signaling in presynaptic retinal ganglion cells mediates axon arbor growth and synapse maturation during the establishment of retinotectal synaptic connectivity. J Neurosci 27:2444-2456.

Martinez-Ferre A, Lloret-Quesada C, Prakash N, Wurst W, Rubenstein JL, Martinez S (2016) Fgf15 regulates thalamic development by controlling the expression of proneural genes. Brain Struct Funct 221:3095-3109.

Mizuno H, Hirano T, Tagawa Y (2007) Evidence for activity-dependent cortical wiring: formation of interhemispheric connections in neonatal mouse visual cortex requires projection neuron activity. J Neurosci 27:6760-6770.

Monavarfeshani A, Stanton G, Van Name J, Su K, Mills WA 3rd, Swilling K, Kerr A, Huebschman NA, Su J, Fox MA (2018) LRRTM1 underlies synaptic convergence in visual thalamus. Elife 7:e33498.

Park H, Poo MM (2013) Neurotrophin regulation of neural circuit development and function. Nat Rev Neurosci 14:7-23.

Salcedo E, Tran T, Ly X, Lopez R, Barbica C, Restrepo D, Vijayaraghavan S (2011) Activity-dependent changes in cholinergic innervation of the mouse olfactory bulb. PLoS One 6:e25441.

Saul SM, Brzezinski JA 4th, Altschuler RA, Shore SE, Rudolph DD, Kabara LL, Halsey KE, Hufnagel RB, Zhou J, Dolan DF, Glaser T (2008) Math5 expression and function in the central auditory system. Mol Cell Neurosci 37:153-169.

Seabrook TA, El-Danaf RN, Krahe TE, Fox MA, Guido W (2013a) Retinal input regulates the timing of corticogeniculate innervation. J Neurosci 33:10085-10097.

Seabrook TA, Krahe TE, Govindaiah G, Guido W (2013b) Interneurons in the mouse visual thalamus maintain a high degree of retinal convergence throughout postnatal development. Neural Dev 8:24.

Seabrook TA, Burbridge TJ, Crair MC, Huberman AD (2017) Architecture, function, and assembly of the mouse visual system. Annu Rev Neurosci 40:499-538.

Sherman SM (2004) Interneurons and triadic circuitry of the thalamus. Trends Neurosci 27:670-675.

Szentagothai J (1963) The structure of the synapse in the lateral geniculate body. Acta Anat (Basel) 55:166-185.

Tschetter WW, Govindaiah G, Etherington IM, Guido W, Niell CM (2018) Refinement of spatial receptive fields in the developing mouse lateral geniculate nucleus is coordinated with excitatory and inhibitory remodeling. J Neurosci 38:4531-4542.

Tucker P, Laemle L, Munson A, Kanekar S, Oliver ER, Brown N, Schlecht H, Vetter M, Glaser T (2001) The eyeless mouse mutation (ey1) removes an alternative start codon from the $\mathrm{Rx} / \mathrm{rax}$ homeobox gene. Genesis 31:43-53.

Turrigiano GG, Nelson SB (2004) Homeostatic plasticity in the developing nervous system. Nat Rev Neurosci 5:97-107.

Verma AS, Fitzpatrick DR (2007) Anophthalmia and microphthalmia. Orphanet J Rare Dis 2:47.

Wang SW, Kim BS, Ding K, Wang H, Sun D, Johnson RL, Klein WH, Gan L (2001) Requirement for math5 in the development of retinal ganglion cells. Genes Dev 15:24-29.

Wee R, Castrucci AM, Provencio I, Gan L, Van Gelder RN (2002) Loss of photic entrainment and altered free-running circadian rhythms in math $5^{-1-}$ mice. J Neurosci 22:10427-10433.

Williams SR, Turner JP, Anderson CM, Crunelli V (1996) Electrophysiological and morphological properties of interneurones in the rat dorsal lateral geniculate nucleus in vitro. J Physiol 490:129-147.

Wilson JR (1986) Synaptic connections of relay and local circuit neurons in the monkey's dorsal lateral geniculate nucleus. Neurosci Lett 66:79-84. 